Paper

\title{
The digital common read: Creating a space for authentic engagement with social annotation
}

\author{
Matthew Wranovix ${ }^{1 *}$ and Mary Isbell ${ }^{2}$ \\ $1 \quad$ University of New Haven, USA; mwranovix@newhaven.edu \\ $2 \quad$ University of New Haven, USA; misbell@newhaven.edu \\ *Correspondence: mwranovix@newhaven.edu
}

Received: 1 October 2019; Accepted: 25 February 2020; Published: 30 June 2020

\begin{abstract}
This paper describes a new approach to the common read at the University of New Haven, USA. Faculty and students choose a text in the public domain, place it on the web, and ask incoming first-year honors students to annotate the text collaboratively using Hypothesis. The choice of text, placement on the web, and editorial introduction can all affect rates of participation and the type of annotations that students choose to share. This method is a low-cost way of creating space for a social intellectual experience prior to arriving on campus.
\end{abstract}

Keywords: common read; social annotation; digital humanities; first-year experience

\section{Introduction}

Colleges and universities in the United States have long sought ways to help incoming firstyear students transition from the relatively narrow horizons of high school to the intellectual curiosity, methods of inquiry, and traditions of academic debate and discussion that lie at the heart of the liberal arts tradition. One tool used to achieve this goal, with varying degrees of success, is the common read, i.e. the selection of a book that all incoming, firstyear students will read over the summer. Committees of faculty and administrators choose each year's text, and institutions often provide the book to students free of charge, a not inconsiderable expense (Kennedy and Boyd, 2018).Typically, the individual, voluntary reading completed by students over the summer is supported by public lectures in the Fall semester or the integration of the text into first-year writing or other courses. In its ideal Platonic form, the common read has much to recommend it; the rich and challenging text selected by faculty provides students with a common intellectual experience prior to arrival on campus, introduces students to a new idea or makes them see something familiar in a new way, and helps students see the importance of sharing ideas. The experience teaches 
students that the life of the mind requires time for individual work and reflection but only comes to full fruition in communication with others.

In our imperfect world, however, the common read rarely lives up to expectations. For committee members who struggle to get students to read assigned texts in class, the temptation to choose easily accessible texts that promote uplifting, but clichéd, messages is high. In the last few years of our university's common read program, the texts chosen included titles such as Start Something that Matters and Make the Impossible Possible, books with messages so anodyne that neither faculty nor students could find anything to discuss, much less debate. Given the potential for profit from the popularity of common read programs on university campuses, it is perhaps unsurprising that publishers promote particular books to the committees tasked with selecting each year's text. We refer to this particular sector of educational publishing as the Common Read Industrial Complex (CRIC), a conglomeration of publishers and booking agencies offering unnecessarily expensive solutions to the challenges facing university common read committees. The allure of preselected, safe texts and the convenience they offer is considerable. However, despite our university's repeated selection of these heavily marketed texts, student participation rates were poor, faculty refused to use the books in their courses (for good reason), and the expense of the books and guest speakers became increasingly hard to justify.

\section{Methods}

Rather than let the program die altogether, we (the authors) decided in 2016 to focus on incoming honors students and turned to the concept of social annotation in a digital environment to reimagine the common read as an interactive experience, one in which students read a text together and can see in real time the thoughts and interpretations of their peers. Our program was inspired by our experimentation with Annotation Studio, a suite of tools created by the Massachusetts Institute of Technology's Hyperstudio, as well as Robin DeRosa's Open Anthology of Earlier American Literature, a project that recreated The Heath Anthology by editing and hosting common domain texts on Pressbooks. DeRosa's project can be placed in the context of scholarship on Computer-Supported Collaborative Learning, a field Hafed Zarzour and Mokhtar Sellami characterize as asking 'how learning can be enhanced through computer mediated collaboration' (Zarzour and Sellami, 2017, p. 383).

Our idea was to choose texts in the public domain, place them on a Pressbooks site, and invite incoming honors students to annotate the text using Hypothesis, a browser plug-in that creates a layer of annotation over the internet. Using Hypothesis, students could highlight text, make annotations, and reply to comments left by others. Recent scholarship has begun to study social annotation tools like Hypothesis to pinpoint how they encourage knowledge construction for students (Sun and Gao, 2017) and how these tools make visible to instructors the way students read (Sprouse, 2018). For our purposes, it was important that the tool allows the creation of closed groups so that only members can read each other's annotations. This new approach did limit us to literature in the public domain, but there were plenty of good options. We also looked for shorter texts in order to maintain a critical density of commentary; were students to annotate a 400-page novel, the annotations would be so far dispersed that the social and interactive nature of the experience would be lost. Our first selection was The Narrative of the Life of Frederick Douglass, a powerful and moving memoir of Douglass' experience as a young enslaved man before his escape in 1838 
(Figure 1). The choice was timely, as that July witnessed large Black Lives Matter protests against the murders of Alton Sterling and Philando Castile at the hands of police officers.

Figure 1. Landing Page for the 2016 Honors Program Common Read

PBPRESSBOOKS

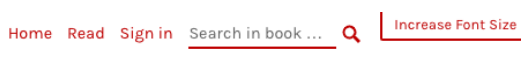

CONTENTS $\quad-\quad$ NARRATIVE OF THE LIFE OF FREDERICK DOUGLASS AN AMERICAN SLAVE. WRITTEN BY
HIMSELF.

HOW TO USE THIS EDITION

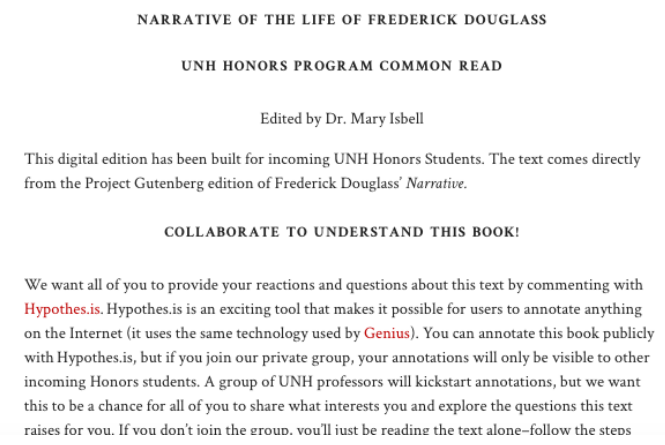

We contacted incoming first-year honors students over the summer with an email invitation to join our digital common read. The email included a link to our Pressbooks site and a video that explained how to install Hypothesis and use the edition. The text itself came from Project Gutenberg. We seeded the text with a handful of annotations so that students could see what they looked like but realized that those were not necessary-students took to Hypothesis more quickly and easily than expected. Students engaged enthusiastically with the text and each other before ever having met in person.

Encouraged by these results, we (the authors) co-taught an honors course the following Spring semester in which the final project was to create webpages for the future of the Honors Program Common Read. Students chose a public domain text, created a Pressbooks site to host it, and wrote an editorial introduction designed to hook readers. Those student projects led to our choice of texts over the next three years: Robert Louis Stevenson's $\underline{T h e}$ Strange Case of Dr. Jekyll and Mr. Hyde (Figure 2); Hans Christian Andersen's "The Little Mermaid" (Figure 3); and Sophocles' Antigone (Figure 4). Hypothesis recently added Blackboard integration, so, for 2019, we built the site in Blackboard to remove the need for students to create separate Hypothesis accounts and to prevent the common mistake of leaving annotations in the default 'public' forum rather than the private common read group in Hypothesis. The hope is that Blackboard integration will make the process more streamlined for students, but one unfortunate consequence is that the page cannot be shared with others in the same way. 
Figure 2. Landing Page for 2017 Honors Program Common Read

\section{EBPRESSBOOKS}

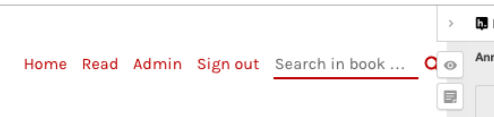

THE STRANGE CASE OF DR. JEKYLL AND MR. HYDE

\begin{tabular}{ll}
\hline & THE STRANGE CASE OF DR. JEKYLL AND MR. HYDE \\
\hline CONTENTS & \\
\hline
\end{tabular}

AN INTERACTIVE READING EXPERIENCE FEATURING
ROBERT LOUIS STEVENSON'S
THE STRANGE CASE OF DR.JEKYLL AND MR. HYDE
Edited by Evgenia Kvitko and Amanda Roche Arbolaez

This edition of the novel was adapted from a digital edition created for Project Gutenberg. It is intended to be used as an interactive and collaborative reading experience among incoming students at the University of New Haven.

$$
\text { A NEW READING EXPERIENCE! }
$$

One of the main goals of this interactive experience is to prompt you to become immersed in the reading by sharing your ideas and reactions about the text as you go through it. This will be possible by adding annotations to the novel using Hypothesis.is, a tool that allows users to annotate anything on the Internet

Figure 3. Landing Page for 2018 Honors Program Common Read

EBPRESSBOOKS

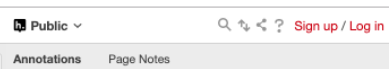

There are no a anotations in this group. Create one by selecting some text and dicking the mb button.

A CHILDREN'S STORY? REALLY?

Each text was the subject of a guest lecture by a university faculty member at the Honors Program Orientation Dinner in August. In 2016, a poet and professor of African-American literature spoke about the continued legacy of slavery in contemporary America; in 2017, a bioethicist helped students think about recent advances in gene-editing; in 2018, a sociologist spoke about his research on gay male choirs and their role in giving gay men in Connecticut a voice and sense of identity; and, in 2019, the campus chaplain and advisor for the President's Public Service Fellowship challenged students to think about the relationship between law and morality. These lectures and the ensuing discussions helped students see the continued relevance of classic literature. 
Figure 4. Landing Page in Blackboard for 2019 Honors Program Common Read

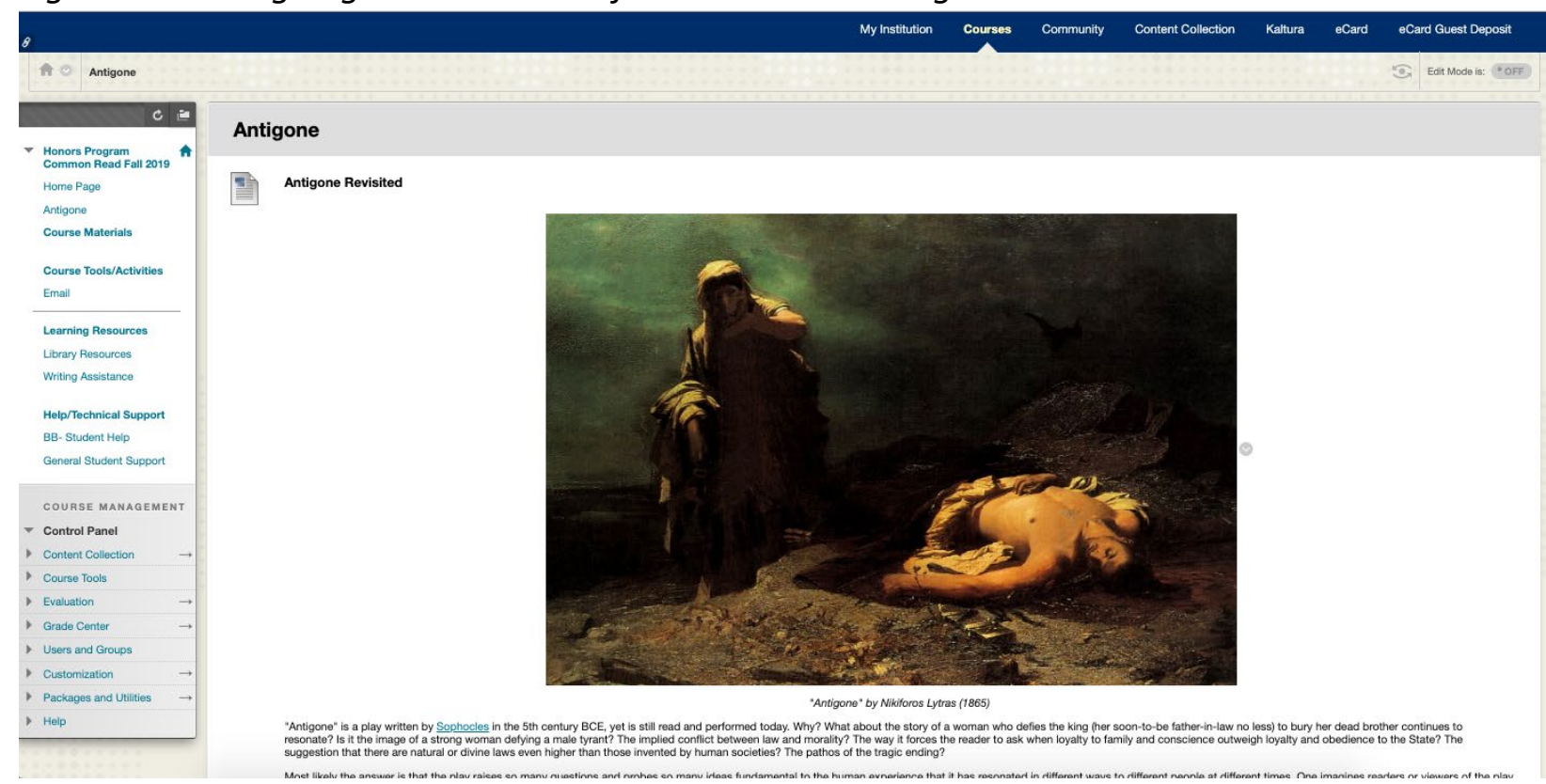

\section{Results}

A significant percentage of students have chosen to participate in the fully optional Honors Program Common Read Program each year. In 2016, 28 students out of a class size of 66 (42\%) left a total of 563 annotations; in 2017, 42 students out of a class size of 128 (33\%) left a total of 821 annotations; in 2018, 67 students (57\%) out of a class size of 118 left a total of 1,082 annotations; and, in 2019, 42 out of a class size of 117 (42\%) left 582 annotations.

Although only a minority of students have chosen to annotate, those that have made that choice have become deeply engaged. The average number of annotations made per student participant has ranged from 14-20.

We have also discovered that the type of editorial introduction strongly affects how students interpret the text or at least affects what kinds of annotations students are willing to share. In 2016, we intentionally kept our introduction to The Narrative of the Life of Frederick Douglass focused on how to use Hypothesis and gave students no interpretive guidance about how to read the text or what to look for. The result was that student annotations were wide-ranging and creative. Students defined terms, explained allusions, expressed outrage, applied historical knowledge, speculated about motives, and marveled at Douglass' skill as a writer. Some compared episodes in the text to novels they had read such as The Hunger Games and Beloved; one saw stylistic echoes in Martin Luther King Jr.'s "Letter from Birmingham Jail." One student compared the function of the alcohol-fueled holidays granted to slaves in nineteenth-century America to the bread and circuses of the Roman Empire. Most, however, made more contemporary connections. One student, the daughter of parents who had immigrated from Latin America, made a powerful comparison between the routine family separations during auctions of the enslaved and modern-day deportations of immigrants; the same student also saw a parallel between the arguments used to oppose the use of free Black carpenters in the nineteenth century and those used to oppose 
immigration today. Horrified by the disparate treatment of free whites and the Black enslaved in the text, some saw links to the Black Lives Matter movement and the issue of how minority communities are policed in the United States. In one long discussion about Douglass' claim that many enslaved people would defend the reputation of their masters when speaking with enslaved people from other plantations, some students applied their knowledge of Stockholm Syndrome, while others compared the phenomenon to the way students will complain about their university to fellow students but defend its reputation when speaking to outsiders.

In 2018, however, we adopted a different strategy. That year, we chose Hans Christian Andersen's fairy tale, "The Little Mermaid." Given the widespread familiarity with the Disney film based on the story, we feared that students might dismiss the text as a story for children and beneath their attention. To demonstrate to students that this was a text worth reading, we provided more guidance than we had in either 2016 or 2017. We provided students with an image of Andersen's autographed manuscript (Figure 5), a page which clearly showed how much he labored over his text.

Figure 5. Page from Andersen's autographed manuscript

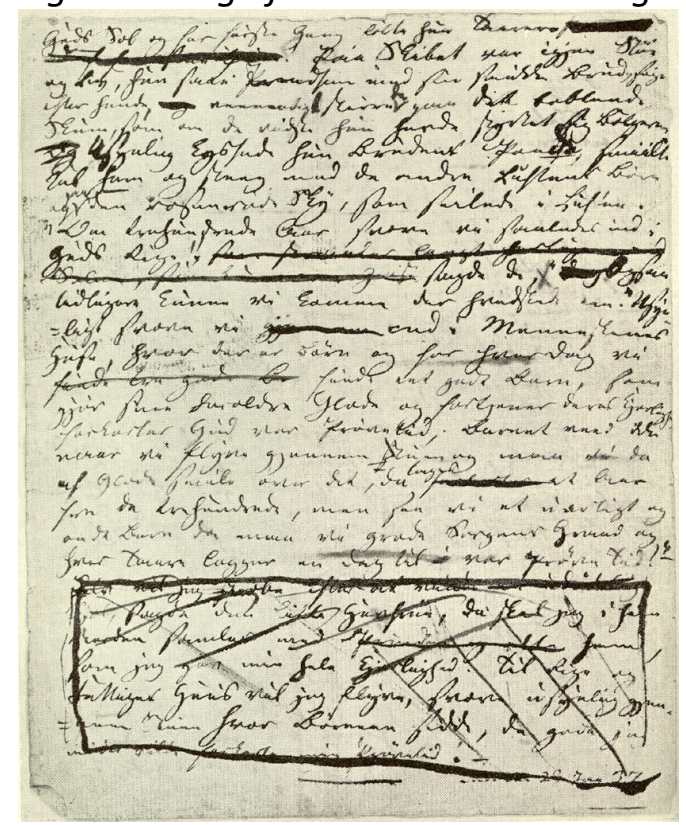

Source:

https://en.wikipedia.org/wiki/The Little Mermaid\#/media/File:Mermaid Last Page.jpg

Inspired by the introduction composed by the student who proposed the text, we also shared the hypothesis by some literary scholars that Andersen's tale was inspired by his unrequited love for another man; according to this interpretation, the mermaid's loss of her voice and the pain she suffers when she pretends to be human symbolizes the plight faced by gay and lesbian men and women in Andersen's society. Our introduction clearly sparked interest in the text, as 2019 saw our highest levels of engagement thus far. But there was a hidden cost to the additional guidance and that was a loss of interpretive freedom; about $39 \%$ of all annotations in 2019 referenced LGBTQ issues and/or the concept of heteronormativity. The power of our introduction was such that students strove to interpret 
even fairly banal details from the story in light of this theme. For example, the very first paragraph inspired storms of commentary:

Far out in the ocean, where the water is as blue as the prettiest cornflower and as clear as crystal, it is very, very deep; so deep, indeed, that no cable could sound it, and many church steeples, piled one upon another, would not reach from the ground beneath to the surface of the water above. There dwell the Sea King and his subjects. (Andersen, p. 124)

No doubt inspired by their high school literature courses, which often (deliberately or not) promote a scramble to identify themes in symbolic imagery, students found plenty to interpret in Andersen's description of the setting. They argued that the blue but clear sea represented both Andersen's sadness and the clarity of the reasons for it; that the depth of the sea symbolized the distance between heterosexual and LGBTQ communities; and that the use of church steeples as a unit of measurement was a commentary on the opposition between Christianity and homosexuality. Andersen's second sentence inspired similar interpretations:

We must not imagine that there is nothing at the bottom of the sea but bare yellow sand. No, indeed, for on this sand grow the strangest flowers and plants, the leaves and stems of which are so pliant that the slightest agitation of the water causes them to stir as if they had life. Fishes, both large and small, glide between the branches as birds fly among the trees here upon land. (Andersen, p. 124)

Here are two typical responses to the above passage:

This paragraph is a critique of heteronormativity, as the sand could be compared to people. In a culture with enforced heteronormativity, people would assume that everyone is heterosexual because they never hear or know otherwise. Here, Andersen says that we must let go of these preconceived notions and embrace the fact that everyone is different and, thus, have different sexualities. These differences are represented by the numerous unique plants and flowers that grow in the sand and the fish that live there.

This shows the separation between homosexuals (fish) gliding in the deep dark, hiding, versus the birds, or heterosexuals, who are free to fly around the land and over the ocean as they please. Birds are often related to the idea of being free. This comparison shows how heterosexuals live free of the constant belittling homosexuals receive. Also the use of the phrase "here upon land" shows normality of the birds/heterosexuals having control over the story and how perspectives are often shown, especially now a days in media.

We can see how powerful this sort of editorial framing can be in one student's annotation, which (consciously or not), began to describe the mermaid as Andersen. Responding to the passage, 'The little mermaid, dressed in silk and gold, held up the bride's train (Andersen, $p$. 163),' the student wrote, 'Although he is dying of heartbreak, Andersen is still devoted to the prince- devoted enough to ironically assist the wedding ceremony that will be the death of 
him.' There were, certainly, other approaches to the text and some students did display some independence. Students wrote about gender roles and social hierarchy, noted discrepancies between the text and the Disney film, and even made links to themes raised by our university's orientation workshops. However, it is clear that our editorial introduction created pressure to read the text a certain way, an observation we explore in greater detail below.

In the Fall 2019 semester, an honors version of our institution's first-year writing course became required for all honors students. In this course, students reflect on the experience of social annotation and have the opportunity to create a pitch to convince the Honors Program Director to select a chosen text as a future Common Read. The benefits of this structure are manifest. Students will have to survey a range of texts and have to consider both the audience for the text itself, future students, as well as for their pitch, a faculty administrator. The projects will also give administrators insight into the kinds of texts students want to read together.

\section{Discussion}

Our goals for the Honors Program Common Read were to create an interactive experience that encouraged students to read carefully, to establish a space for students to learn from each other, and to help students realize that true scholarship means entering into a conversation with others. Social annotation of public domain texts using Hypothesis has helped us achieve those goals and has encouraged us to refine them.

Students are able to build and share expertise; we have had students identify and explain biblical references in Narrative of the Life of Frederick Douglass, while another researched and reported back on the cultural importance of cornflowers to interpret a seemingly meaningless detail in Andersen's fairy tale. Even before students arrive on campus, they can begin to craft an identity as scholars and experts rather than passive learners. It is important to note, of course, that this activity can still prompt student engagement that seems less about expressing genuine responses and more about demonstrating an ability to find the "right" answer.

Hypothesis provides a medium for students to encounter their peers' thoughts, while encouraging students to pay attention to particular words, phrases, and passages. We now recognize that we want to help students do this work in a way that prepares them to expand beyond the habits of learning that might have developed in prior educational settings. For example, the overzealous interpretation of "The Little Mermaid," clearly guided by our more directive editorial introduction, deserves some reflection. Did our editorial introduction incentivize students to pursue the correct answer rather than truly engage with the story? Stanley Fish has questioned this approach to teaching literature in his seminal Is There a Text in This Class? The Authority of Interpretive Communities, which offers a critique all the more relevant as we invite students to engage in social annotation.

Fascinating in "The Little Mermaid" iteration of the Honors Common Read, however, is the fact that students enthusiastically carried out this task while participating in a voluntary activity that would not receive a formal grade. There are many ways to think about this behavior that will be of interest to honors administrators and faculty educators alike. First, 
we might suggest that students see the Honors Common Read, though voluntary, as a highstakes activity in which they need to prove themselves worthy of inclusion in the program; essentially, this overzealous interpretation is a symptom of the ever-present imposter syndrome common to incoming honors students. It is also possible (though, we think, less likely) that students have so internalized the interpretive techniques they were taught in literature classes that they approach all texts in this way. A more in-depth study of student annotations will provide additional insight into this issue, but for the purposes of this article, it seems useful to remember that we are often working with students who are putting tremendous effort into assuming their new role as honors students; if we want to push them to bring their own ideas and (potentially unexpected or even irreverent) responses to the discussion, we should be careful not to inadvertently ask for a performance of literature skills students think we want to see.

One of our primary motivations for building a common read for the Honors Program is that we want to encourage students to recognize that the university invites us all to participate in the life of the mind both inside and outside of formal classrooms. We want them to attend lectures and engage in discussions not because they are requirements but because they are genuinely interested in the topics being discussed. One benefit of our approach to the common read is the insight it provides into what does or does not resonate with students. While the social annotation of a text certainly sets a productive experience in motion, benefits truly emerge when the texts have been chosen by students. The annotated versions of the common read text are now being integrated into assignments in the honors version of first-year writing so that faculty instructors can help students think about what it means to read a text closely, how research questions affect interpretations, and how considerations of audience affect style. As mentioned above, these first-year students will be given an opportunity to propose future common read texts. Our initial group of texts were selected by students who had graduated by the time their recommendations were implemented, but encouraging first-year students to suggest texts makes it more likely that those students can be involved in planning the in-person common read events incorporated into orientation activities.

We suspect that housing the common read within Blackboard (as opposed to a public website built with Pressbooks) inevitably positions it as an assignment. The images above illustrate the very different look and feel created by the two platforms. The fact that the texts will also be incorporated into course assignments also sends this message. Honors administrators interested in adopting this approach to the common read will need to consider whether a public Pressbooks site or a closed Learning Management System makes the most sense for hosting the chosen text. Administrators should also note that we plan to refine our approach to account for recent research suggesting that integrating linked-open data into the social annotation experience can enhance the positive outcomes we have noted (Zarzour and Sellami, 2017, p. 386). The way the text is presented to students will also have a profound effect on how students approach it and the type of commentary they will share.

Though the frame for the activity and the methods used to invite student participation must be selected with care, social annotation of public domain texts is a low-cost method of achieving the goals of common read programs. Students are afforded an intellectual 
experience both personal yet shared and are invited to help craft that same experience for their peers in the future.

\section{References}

Andersen, H. C. (1915). Hans Andersen's Fairy Tales (J. H. Stickney, ed.). Ginn and Company. (Original work published 1837). Retrieved from https://www.gutenberg.org/files/32572/32572-h/32572-h.htm

Annotation Studio. Retrieved from https://www.annotationstudio.org/

DeRosa, R. The Open Anthology of Early American Literature. Retrieved from https://openamlit.pressbooks.com/

Fleerackers, A., Alperin, J. P., Morales, E., \& Kalir, R. (2019). Comment, reply, repeat: Engaging students with social annotation. Retrieved from https://www.scholcommlab.ca/2019/08/27/social-annotation/.

Fish, S. (1980). Is There a Text in this Class? Cambridge: Harvard University Press.

Howard, J. (2012). With 'social reading,' books become places to meet. The Chronicle of Higher Education. Retrieved from https://www.chronicle.com/article/Social-ReadingProjects/135908/.

Kennedy, E. H. \& Boyd, A. (2018). Gendered citizenship and the individualization of environmental responsibility: evaluating a campus common reading program. Environmental Education Research, 24(2), 191-206.

Sprouse, M. (2018). Social Annotation and Layered Readings in Composition. In Chen Chen, Kristopher Purzycki, and Lydia Wilkes (Eds.), Proceedings of the Annual Computers and Writing Conference (pp. 39-52). Fort Collins, Colorado: The WAC Clearinghouse.

Sun, Y. \& Fei Gao. (2017). Comparing the use of social annotation tool and a threaded discussion forum to support online discussions. The Internet and Higher Education, 32, 7279.

Zarzour, H. \& Sellami, M. (2017). A linked data-based collaborative annotation system for increasing learning achievements. Educational Technology Research \& Development, 65(2), 381-397. 